\title{
Identical Twins with Long QT Syndrome Associated with a Missense Mutation in the S4 Region of the HERG
}

\author{
Kenshi Hayashi, MD, Masami Shimizu, MD, Hidekazu Ino, MD, \\ Kazuyasu OKeIE, MD, Masato Yamaguchi, MD, \\ Toshihiko Yasuda, MD, Noboru Fujino, MD, \\ Hiroyuki FuJII, MD, Shinichiro FuJITA, MD, \\ and Hiroshi MABUCHI, MD
}

\begin{abstract}
SUMMARY
Familial long QT syndrome (LQTS) is caused by mutations in genes encoding ion channels important in determining ventricular repolarization. Mutations in at least five genes have been associated with the LQTS. Fire genes, KCNQ1, HERG, SCN5A, KCNE1, and KCNE2, have been identified. We have identified a missense mutation in the HERG gene in identical twins in a Japanese family with LQTS. The identical twins in our study had QT prolongation and the same missense mutation. However only the proband had a history of syncope. Although many mutations in LQT genes have been reported, there are few reports of twins with LQTS. This is the first report, to our knowledge, of identical twins with a HERG gene mutation. (Jpn Heart J 2000; 41: 399-404)
\end{abstract}

Key words: LQTS, HERG gene mutation, Identical twin, Long QT syndrome, Romano-Ward Syndrome

FAMILIAL long QT syndrome ([LQTS]: Romano-Ward syndrome and Jervell and Lange-Nielsen syndrome), an inherited cardiac disorder that results in syncopal attacks and sudden death, ${ }^{1)}$ is characterized by prolongation of the QT interval indicating abnormal cardiac repolarization. Genetic linkage analysis has revealed that the autosomal dominant form of LQTS is genetically heterogeneous. At least 6 LQTS loci have been identified:-9) $11 \mathrm{p} 15.5$ (LQT1), 7q35-36 (LQT2), 3p21-24 (LQT3), 4q25-27 (LQT4), 21q22.1-22.2 (LQT5), and 2lq 11.1 (LQT6). While identical twins have the same genotype (genetic abnormality) and phenotype (LQTS), only a few reports of identical twins with the genotype and phenotype have been published. ${ }^{10-13)}$ In this report, we describe a missense mutation in the S4

From the Second Department of Internal Medicine, School of Medicine, Kanazawa University, Kanazawa, Japan.

Address for correspondence: Kenshi Hayashi, MD, Second Department of Internal Medicine, School of Medicine, Kanazawa University, Takara-machi 13-1, Kanazawa 920-8640, Japan.

Received for publication January 6, 2000.

Revised and accepted February 14, 2000. 
region of the HERG in identical twins with long QT syndrome.

\section{METHODS}

Case Report: The proband is a 28-year-old Japanese male who experienced syncopal episodes while sleeping. He was admitted to our hospital for evaluation. Physical examination, hematologic examination, urinalysis, and audiometrics were normal. Serum $\mathrm{K}, \mathrm{Mg}$, and $\mathrm{Ca}$ concentrations were also within normal limits. He had a QTc interval of 0.49 seconds (Figure 1), corresponding to a score of 6 points based on the 1993 LQTS criteria, ${ }^{14)}$ which confirmed a diagnosis of LQTS. The QTc intervals during and after treadmill exercise test increased significantly (Figure 2). The proband has an identical twin brother. The brother and his mother had QTc inervals of 0.51 and 0.47 seconds, respectively (Figure 1) but did not have a history of syncope. The electrocardiograms of the father and elder brother of the proband were within normal limits (Figure 1).

DNA Isolation and Mutation Analysis: Genomic DNA was purified from white blood cells obtained from family members, and in vitro amplifications of genomic DNA were performed by polymerase chain reaction (PCR). ${ }^{15)}$ Oligonucleotide primers used for the amplification were based

Proband
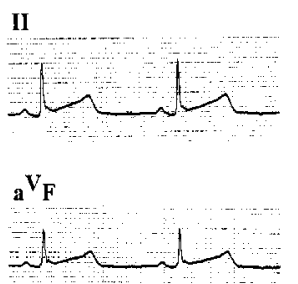

$v_{2}$

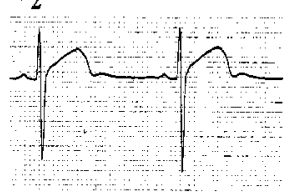

$\mathrm{v}_{5}$

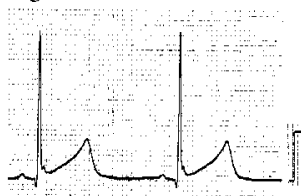

Twin brother
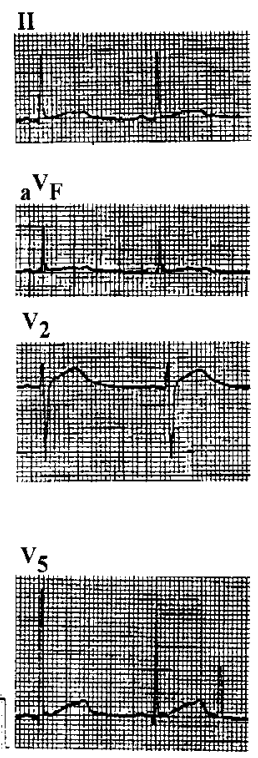

Father
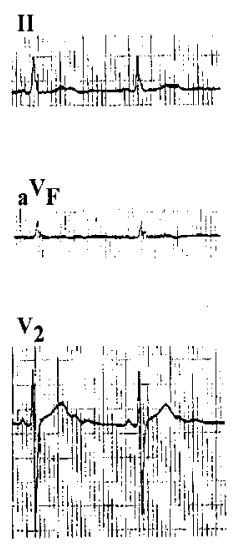

$v_{5}$

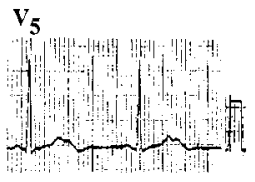

Elder broder
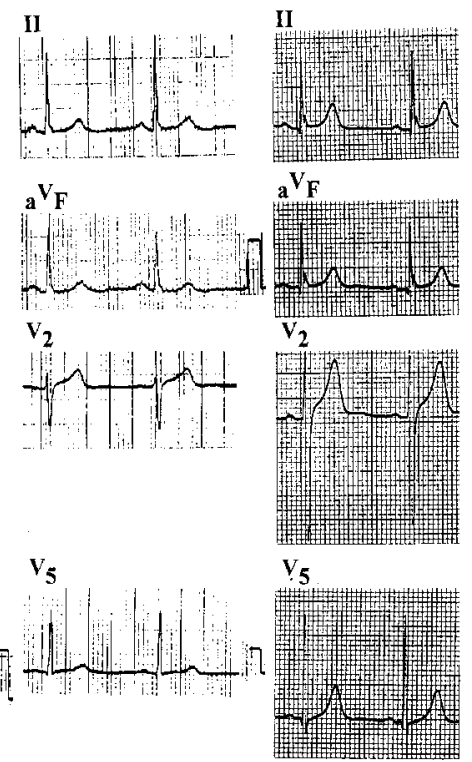

Figure 1. Electrocardiograms (leads II, $a V_{F}, V_{2}$ and $V_{5}$ ) from the LQTS family members. 
Before exercise
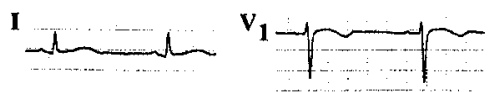

II

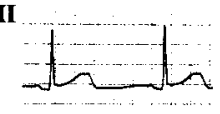

III

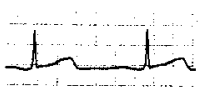

$v_{2}$

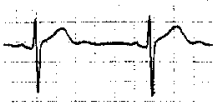

$\mathbf{v}_{3}$
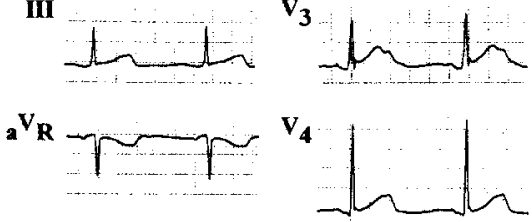

$\mathbf{a}_{\mathbf{L}}$
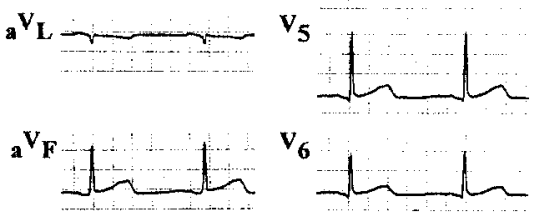

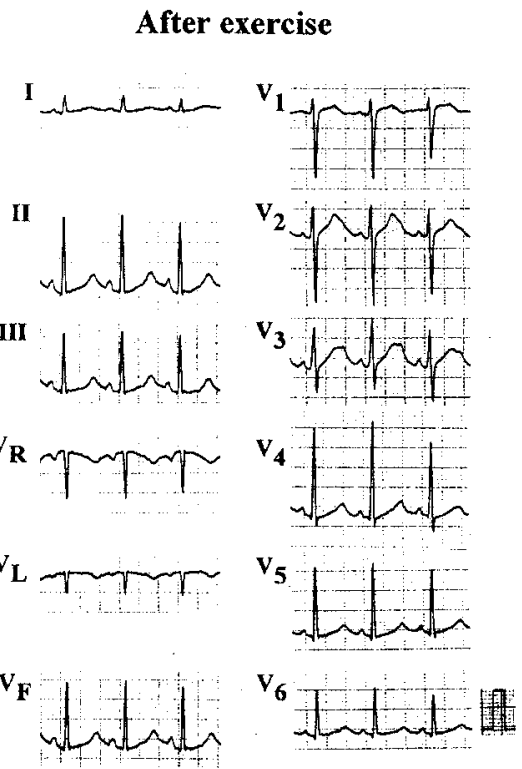

Figure 2. Twelve-lead electrocardiograms of the proband at rest and after symptom-limited maximal effort treadmill test. The QTc intervals increased from 0.47 seconds at rest to 0.60 seconds after exercise.

on published sequences. ${ }^{4)}$ Single-strand conformational polymorphism (SSCP) analysis of the amplified DNA was performed to screen for mutations in KCNQ1, HERG, and SCN5A as described previously, ${ }^{16)}$ with a slight modification. ${ }^{17)}$ DNA sequencing was conducted with ABI PRISM 310 (PE Applied Biosystems, Foster City, CA, USA).

\section{RESULTS}

Screening for mutations in the HERG gene with SSCP analysis identified an abnormal SSCP conformer in the twins and the mother in this Japanese family (Figure 3A), but not in $>100$ control individuals. Sequence analysis of the abnormal SSCP conformer revealed a nucleotide substitution $(\mathrm{C} \rightarrow \mathrm{G})$ in the S4 region which was predicted to substitute cysteine for arginine at codon 534 (R534C; Figure 3B). This missense mutation has been previously described. ${ }^{18)}$ Screening for mutations in the KCNQ1 and SCN5A with SSCP did not show any abnormal SSCP conformers compared to control (data not shown). 

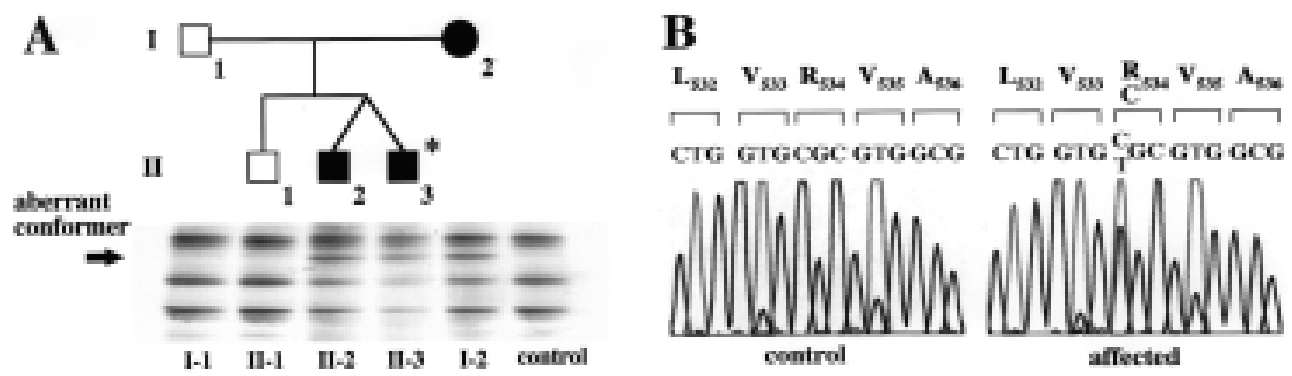

Figure 3. Mutation analysis. A: The pedigree and SSCP analysis. Open squares represent unaffected males, and closed circle and squares denote affected female and males, respectively. The aberrant conformer in I-2, II2, and II-3 is indicated by an arrow. B: DNA sequence analysis of normal control and aberrant conformers reveals a nucleotide substitution in the proband, his mother, and his twin brother. Transition occurs in the fourth membrane-spanning domain of the HERG protein, leading to a missense mutation.

\section{DisuCUSSION}

In this report, we identified a missense mutation in the HERG gene associated with LQTS in a Japanese family that includes identical twins with LQTS. LQTS twins have been reported previously. ${ }^{10-13)}$ Among these investigators, only Russell, et al. ${ }^{13)}$ performed mutational analysis, and they demonstrated mutation of the KCNQI gene in monozygotic twin offspring of unaffected parents. Our study is the first to describe identical twins with HERG gene mutation.

Greenspon, et al. ${ }^{10)}$ described a set of triplets which included two identical siblings with symptomatic congenital LQTS. The identical siblings had similar symptoms and electrocardiographic abnormalities, while the fraternal sibling was asymptomatic and had a normal electrocardiogram. The identical twins in our study had QT prolongation and the same missense mutation, but only the proband had a history of syncope.

Syncope in patients with long QT syndrome is frequently associated with an abrupt increase in sympathetic activity, such as that caused by emotional stress or physical activity. According to Nakajima, et al., ${ }^{19)}$ auditory stimuli may trigger cardiac adrenergic activity and may be a significant risk factor for ventricular tachyarrhythmias and subsequent cardiac syncope or sudden cardiac death. Moreover, according to Wilde, et al. ${ }^{20)}$ arrhythmic events triggered by auditory stimuli may differentiate LQTS2 from LQTS1 patients. They ${ }^{20)}$ described that in 9 out of 15 symptomatic gene carriers in HERG-based families, acoustic stimuli were related to syncope, but none of the 23 symptomatic carriers of a mutated KCNQ1 gene reported syncope related to auditory stimuli.

In our study, the proband had experienced two syncopal episodes at 26 years of age and at 28 years of age, with the former event occurring around midnight and 
the latter early in the morning. He did not use an alarm clock, but syncope may have occurred when he was awakened by a noise at night or early in the morning. Differences in the environment may be responsible for differences in the phenotype of these identical twins. Nevertheless, the twin brother of the proband should be monitored for cardiac events because he is at high risk for experiencing such events.

The R534C substitution is found in the S4 region of the HERG. In a previous study, Itoh, et al ${ }^{18)}$ reported this mutation in five patients in three generations of a Japanese family with LQTS. Arginine in the S4 region of the HERG is highly conserved in this gene and is thought to function as a voltage sensor, which is one of the key functions required of an ion channel.

In conclusion, we have identified a missense mutation in the HERG gene in identical twins in a Japanese family with LQTS. There are few reports of twins with LQTS, and this is the first report, to our knowledge, of identical twins with a HERG gene mutation.

\section{REFERENCES}

1. Moss AJ, Schwartz PJ, Crampton RS, et al. The long QT syndrome: prospective longitudinal study of 328 families. Circulation 1991; 84: 1136-44.

2. Keating M, Atkinson D, Dunn C, Timothy K, Vincent GM, Leppert M. Linkage of a cardiac arrhythmia, the long QT syndrome, and the Harvey ras-1 gene. Science 1991; 252: 704-6.

3. Jiang C, Atkinson D, Towbin JA, et al. Two long QT syndrome loci map to chromosome 3 and 7 with evidence for further heterogeneity. Nat Genet 1994; 8: 141-7.

4. Curran ME, Splawski I, Timothy KW, Vincent GM, Green ED, Keating MT. A molecular basis for cardiac arrhythmia: HERG mutations cause long QT syndrome. Cell 1995; 80: 795-803.

5. Wang Q, Shen J, Splawski I, et al. SCN5A mutations associated with an inherited cardiac arrhythmia, long QT syndrome. Cell 1995; 80: 805-11.

6. Schott J, Charpentier F, Peltier S, et al. Mapping of a gene for long QT syndrome to chromosome 4q25-27. Am J Hum Genet 1995; 57: 1114-22.

7. Wang Q, Curran ME, Splawski I, et al. Positional cloning of a novel potassium channel gene:KVLQT1 mutations cause cardiac arrhythmias. Nat Genet 1996; 12: 17-23.

8. Splawski I, Tristani-Firouzi M, Lehmann MH, Sanguinetti MC, Keating MT. Mutations in the hminK gene cause long QT syndrome and suppress Iks function. Nat Genet 1997; 17: 338-340.

9. Abbott GW, Sesti f, Splawski I, et al. MiRP1 forms $\mathrm{I}_{\mathrm{kr}}$ potassium channels with HERG and is associated with cardiac arrhythmia. Call 1999; 97: 175-87.

10. Greenspon AJ, Kidwell GA, Barrasse LD, Hessen SE, Giudici M. Hereditary long QT syndrome associated with cardiac conduction system disease. PACE 1989; 12: 479-85.

11. Jacobson J, Jacobson C, Francis P. Congenital hearing loss in Jervell and Lange-Nielsen syndrome. J Am Acad Audiol 1990; 1: 171-3.

12. Wilknson C, Gyaneshwar R, Mccusker C. Twin pregnancy in a patient with idiopathic long QT syndrome. Case report. Br J Obstet Gynaecol 1991; 98: 1300-2.

13. Russell MW, Dick MII, Collins FS, Brody LC. KVLQT1 mutations in three families with familial or sporadic long QT syndrome. Hum Molec Genet 1996; 5: 1319-24.

14. Schwartz PJ, Moss AJ, Vincent GM, Crampton RS. Diagnostic criteria for the long QT syndrome: an update. Circulation 1993; 88: 782-4. 
15. Haliassos A, Chomel JC, Tesson L, et al. Modification of enzymatically amplified DNA for the detection of point mutations. Nucleic Acids Res 1989; 17: 3606.

16. Orita M, Suzuki Y, Sekiya T, Hayashi K. Rapid and sensitive detection of point mutation and DNA polymorphisms using the polymerase chain reaction. Genomics 1989; 5: 874-9.

17. Mohabeer AJ, Hiti AL, Martin WJ. Non-radioactive single strand conformation polymorphism (SSCP) using the Pharmacia 'PhastSystem'. Nucleic Acids Res 1991; 19: 3154.

18. Itoh T, Tanaka T, Nagai R, et al. Genomic organization and mutational analysis of HERG, a gene responsible for familial long QT syndrome. Hum Genet 1998; 102: 435-9.

19. Nakajima T, Misu K, Iwasawa K, et al. Auditory stimuli as a major cause of syncope in a patient with idiopathic long QT syndrome. Jpn Circ J 1995; 59: 241-6.

20. Wilde AAM, Jongbloed RJE, Doevendans PA, et al. Auditory stimuli as a trigger for arrhythmic events differentiate HERG-related (LQTS2) patients from KVLQT1-related patients (LQTS1). J Am Coll Cardiol 1999; 33: $327-32$. 
